\title{
FATIGUE STRENGTH OF NITRIDED STEELS IN CORROSION-ACTIVE MEDIA OF THE FOOD ENTERPRISES
}

\author{
M.S.Stechyshyn, ${ }^{1,2}$ M. E.Skyba, ${ }^{1}$ Yu. G. Sukhenko, ${ }^{3}$ and M. I. Tsepenyuk ${ }^{4}$ \\ We study the effects of the modes of nitriding in glow discharge on the low- and high-cycle fatigue of \\ structural steels in acid, alkaline, and neutral model solutions and in air.
}

Keywords: nitriding in glow discharge, low- and high-cycle fatigue strengths, stress-corrosion wear, corrosive media.

\section{Introduction}

The electrochemical fatigue fracture of metals under the conditions of stress-corrosion wear in corrosive media (CM) of the food enterprises [1] requires the investigation of the fatigue characteristics of metals. However, these characteristics are studied quite poorly, which restricts the possibilities of development of scientifically substantiated recommendations for the choice of friction units in technological installations used in the food industry.

The aim of the present work is to study the influence of the modes of nitriding in glow discharge (NGD) on the fatigue life and strength of nitrided structural steels in model corrosive media of food enterprises.

\section{Methods of Investigations}

The NGD was carried out in a UATR-1 installation designed and produced at the research-experimental base of the Podil's'kyi Scientific-Technological Center of the Khmelnytskyi National University [2]. The diode-type DC UATR-1 installation operates in waterless gaseous media. It is additionally equipped with heating elements placed in a gas-discharge chamber, which enables one to arbitrarily vary the voltage and the current density [3].

To study the low-cycle lifetime, we used a modernized installation IP-2 designed at Karpenko Physicomechanical Institute of the Ukrainian National Academy of Sciences [4]. On this installation, we tested plane specimens for the pure bending by a stiff loading scheme. The specimens were subjected to the elastoplasic deformation by bending with a frequency of $0.38 \mathrm{sec}^{-1}$. The high-cycle durability was studied on a vibration stand VÈDS-200 with electromagnetic excitation. The specimens were bent by the cantilever scheme at a resonance with the first form of vibrations [5].

\footnotetext{
${ }^{1}$ Khmelnytskyi National University, Khmelnytskyi, Ukraine.

2 Corresponding author; e-mail: m-mezon@ukr.net.

${ }^{3}$ Ukrainian National University of Bioresources and Nature Management, Kiev, Ukraine.

${ }^{4}$ Pulyui Ternopil National Technical University, Ternopil, Ukraine.
}

Translated from Fizyko-Khimichna Mekhanika Materialiv, Vol. 55, No. 1, pp. 125-129, January-February, 2019. Original article submitted September 14, 2018. 
Table 1

Low-Cycle Lifetime under the Elastoplastic Deformation of Specimens $(\varepsilon=0.75 \%)$ in an Acidic Medium for Different NGD Modes

\begin{tabular}{c|c|c|c|c|c|c|c|c|c|c|c}
\hline \multirow{3}{*}{ Steel } & \multicolumn{10}{c}{ Number of cycles $N$ prior to fracture } \\
\cline { 2 - 14 } & \multicolumn{3}{|c}{ Temperature, ${ }^{\circ} \mathrm{K}^{1}$} & \multicolumn{3}{c}{ Content of nitrogen, $\%{ }^{2}$} & \multicolumn{4}{c}{ Pressure, $\mathrm{Pa}^{3}$} \\
\cline { 2 - 14 } & 793 & 833 & 873 & 45 & 60 & 75 & 90 & 100 & 80 & 265 & 450 \\
\hline 38 KhMYuA & 3190 & 2485 & 2030 & 2412 & 2415 & 2460 & 2458 & 2485 & 2400 & 2460 & 2450 \\
$40 \mathrm{Kh}$ & 3150 & 2390 & 1690 & 2400 & 2405 & 2430 & 2395 & 2398 & 2386 & 2430 & 2427 \\
45 & 2840 & 2620 & 2480 & 2630 & 2620 & 2640 & 2642 & 2620 & 2600 & 2640 & 2630 \\
20 & 2700 & 2540 & 2410 & 2510 & 2520 & 2540 & 2550 & 2540 & 2520 & 2540 & 2540 \\
\hline
\end{tabular}

Comments: $1.100 \% \mathrm{~N}_{2}, 265 \mathrm{~Pa}, 2.833^{\circ} \mathrm{K}, 265 \mathrm{~Pa}, 3.833{ }^{\circ} \mathrm{K}, 75 \% \mathrm{~N}_{2}+25 \% \mathrm{Ar}$.

According to work [5], the disjoining action of oxides in the fatigue tests in CM affects insignificantly the cracks with sizes $>2.5 \mathrm{~mm}$ and strongly at the early stages of their propagation. Therefore, we ceased the test, if the crack length attained $0.5 \mathrm{~mm}$. We accepted $10^{7}$ and $5 \cdot 10^{7}$ loading cycles as the bases of tests in air and in $\mathrm{CM}$, respectively. The influence of a strengthening on the cyclic durability was determined on specimens with stress concentrators which were cut before the nitriding.

The degree of influence of the diffusion coatings on the durability of details is closely related to their strength properties. The strength of nitrided specimens was tested on an installation "ALA-TOO" of the IMASh-20-75 type. The loading evenness was $1.5 \%$ of the applied load, which ensures the mean rate of deformation to be $3.3 \cdot 10^{-6} \mathrm{~m} / \mathrm{sec}$ if the error of the movement velocity of a specimen holder is $1 \%$. The ultimate strength was determined by the largest load preceding the fracture of a specimen.

We studied 20,45, 40Kh, and 38KhMYuA steels, by using the metallographic, electron-microscopic, and $\mathrm{X}$-ray diffraction analyses. We carried out the tests for the fatigue durability in buffer aqueous solutions which model the majority of working media at food enterprises: neutral (condensate in evaporators), acidic (bisubstituted sodium phosphate $\mathrm{Na}_{2} \mathrm{HPO}_{4}-10 \mathrm{~g} /$ liter, citric acid $\mathrm{C}_{2} \mathrm{H}_{8} \mathrm{O}_{7}-5 \mathrm{~g} /$ liter), and alkaline (calcium oxide $\mathrm{CaO}-250 \mathrm{~g} /$ liter and sucrose $-15 \%$ of the mass of $\mathrm{CaO}$ ) media.

\section{Results and Discussion}

The studies of the low-cycle lifetime of nitrided steels showed (Table 1) that the nitriding temperature has the highest effect on the lifetime: the low-cycle lifetime decreases, as the temperature increases. The tests for static strength indicate that NGD causes some increase in the static strength characteristics of 20, 45, and $38 \mathrm{KhMYuA}$ steels and an insignificant decrease for $40 \mathrm{Kh}$ steel. At the same time, the plasticity of the studied steels decreases significantly, which is caused by an increase in the hardness of the surface layer as a result of NGD (Table 2). It is established (see Table 1) that the durability limit for nitrided steels increases with the strength of a core. We note that the fracture foci are usually placed under the surface layer during the nitriding. Therefore, the nitride zone composition insignificantly affects the fatigue characteristics, and an increase in 


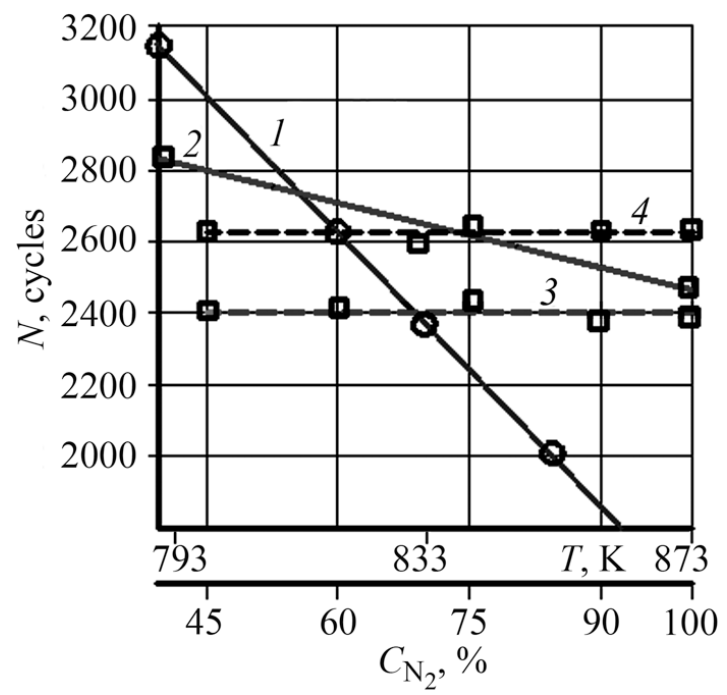

Fig. 1. Dependences of the number of cycles before the fracture of specimens at a low-cycle loading $(\varepsilon=0.75 \%)$ in the acidic environment on the temperature $(1,2)$ and on the nitrogen content $(3,4)$ under NGD: $(1,3) 40 \mathrm{Kh}$ steel, $(2,4) 45$ steel.

Table 2

Mechanical Properties of Steels

\begin{tabular}{c|c|c|c|c|c}
\hline Steel & $\sigma_{\mathrm{y}}, \mathrm{MPa}$ & $\sigma_{\mathrm{u}}, \mathrm{MPa}$ & $\delta, \%$ & $\psi, \%$ & $A, \mathrm{kN} \cdot \mathrm{m} / \mathrm{m}^{3}$ \\
\hline 38KhMYuA & $880 / 950$ & $1050 / 1200$ & $9 / 5$ & $40 / 20$ & $85 / 50$ \\
$40 \mathrm{Kh}$ & $840 / 830$ & $1000 / 1000$ & $10 / 6$ & $50 / 25$ & $90 / 50$ \\
45 & $340 / 450$ & $580 / 670$ & $15 / 10$ & $40 / 30$ & $70 / 60$ \\
20 & $230 / 330$ & $390 / 500$ & $20 / 15$ & $55 / 40$ & $65 / 60$ \\
\hline
\end{tabular}

Comments: Numerator - improved steel; denominator - nitrided steel (833 $\left.{ }^{\circ} \mathrm{K}, 75 \% \mathrm{~N}_{2}+25 \% \mathrm{Ar}, 265 \mathrm{~Pa}\right)$.

the resistance to a low-cycle deformation is mainly determined by the strength characteristics of a core. However, the significant factor for the improvement of the fatigue durability is the diffusion layer thickness. Its decrease [6] and the simultaneous increase in the strength of a core result in an increase in the number of cycles prior to the fracture under a low-cycle load.

The application of the method of active planning of experiments enabled us to develop a statistical model of low-cycle lifetime of $40 \mathrm{Kh}$ steel in an acidic medium $(\varepsilon=0.5 \%)$ :

$$
Y=4.90-0.20 x_{1}+0.03 x_{2}+0.03 x_{3}
$$

where $x_{1}$ is the NGD temperature, $x_{2}$ is the content of nitrogen in a gas mixture, and $x_{3}$ is its pressure.

The analysis of the developed model shows that the nitriding temperature has the highest statistical influence on the low-cycle durability. As it increases, the durability of specimens decreases. On the contrary, an increase in the content of nitrogen in a gas mixture and in its pressure increases slightly the fatigue durability of 45 and $40 \mathrm{Kh}$ steels under a low-cycle loading (Fig. 1). 


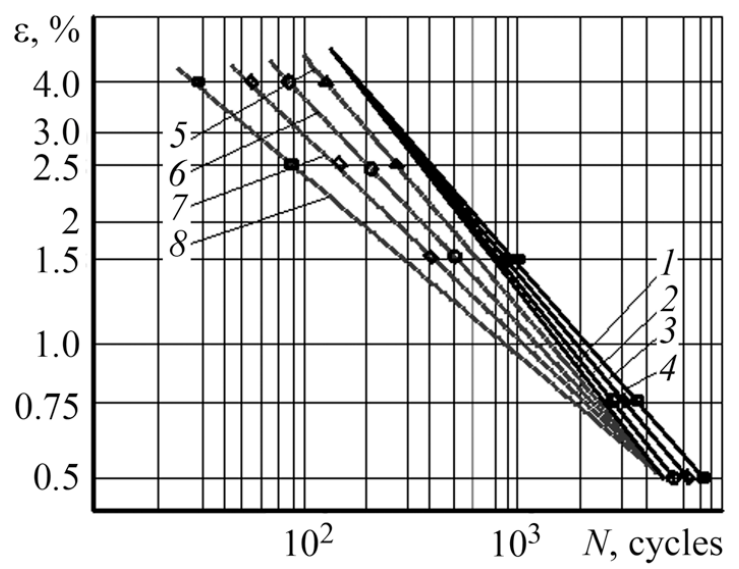

Fig. 2. Resistance to a low-cycle loading of nonhardened (1-4) and nitrided $\left(833{ }^{\circ} \mathrm{K}, 75 \% \mathrm{~N}_{2}+25 \% \mathrm{Ar}, 265 \mathrm{~Pa}\right)(5-8) 40 \mathrm{Kh}(1,8)$, $38 \mathrm{NMYuA}(2,7), 45(3,5)$, and 20 steels $(4,6)$ in an acidic model environment.

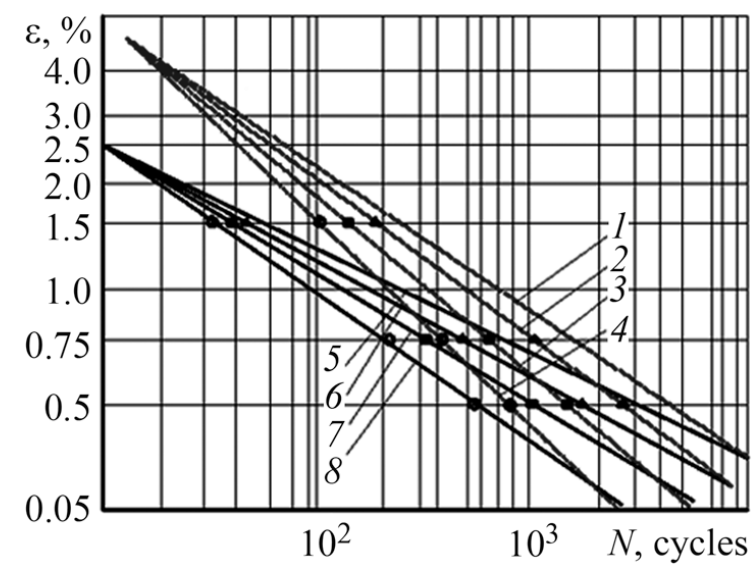

Fig. 3. Resistance to a low-cycle loading of improved (1-4) and nitrided ( $833{ }^{\circ} \mathrm{K}, 75 \% \mathrm{~N}_{2}+25 \%$ Ar, $\left.265 \mathrm{~Pa}\right) 40 \mathrm{Kh}$ steels (5-8) in the following media: $(1,5)$ alkaline, $(2,6)$ air, $(3,7)$ neutral (condensate with $\mathrm{pH} 7$ in evaporators), $(4,8)$ acidic $(\mathrm{pH} 6.5)$ media.

It is established that, as the deformation amplitude increases, the difference in the lifetimes of nonhardened steels decreases and practically disappears at $\varepsilon \geq 3 \%$. It is obvious that its action is stronger than the influence of the structure and the strength characteristics of the studied steels. In this case, a steel with higher specific work $A$ of a deformation (Table 2) has a higher fatigue durability under a low-cycle loading (Fig. 2, curves 1 and 4). As is seen (Figs. 2 and 3), NGD is not efficient for all media for $\varepsilon>0.25 \%$. Under a low-cycle loading, the general regularity is a decrease in the lifetime of steels, as their plasticity decreases. Therefore, NGD decreases the number of loading cycles prior to the fracture (Table 2), by decreasing the plasticity. In this case, the firmer the nitrided steel, the faster its durability decreases in acidic media. This is explained by an increase in a shift of the potential to the negative side at higher deforming stresses which are always higher in firmer steels. This results in an acceleration of the corrosion and in the hydrogen embrittlement at the tips of cracks.

Our analysis shows (Fig. 3) that the number of cycles prior to the fracture under a low-cycle loading of nitrided and nonhardened steels in alkaline media is higher than in air, condensate of evaporators, and acidic media. An increase in the low-cycle fatigue durability in an alkaline medium as compared with the durability in air is explained by the formation of a hydroxide layer on the surface of specimens. This hampers the access of oxygen to the deformation zone and blocks the rise of dislocations to the surface. 


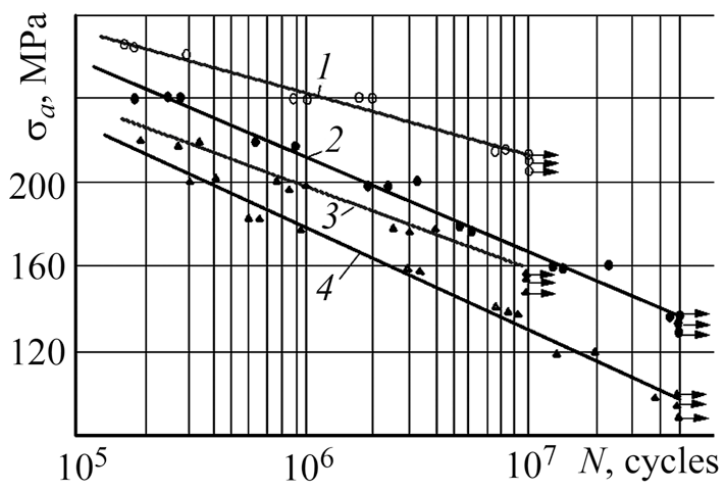

Fig. 4. Resistance to the high-cycle loading of nitrided $\left(833{ }^{\circ} \mathrm{K}, 75 \% \mathrm{~N}_{2}+25 \% \mathrm{Ar}, 265 \mathrm{~Pa}\right)(1,2)$ and improved $(3,4)$ specimens made of $40 \mathrm{Kh}$ steel in air $(1,3)$ and in an acidic medium $(2,4)$.

The fatigue durability in a condensate in evaporators which has a lower corrosion activity as compared with acidic media slightly increases. However, as the deformation amplitude increases, the influence of the corrosion activity of a medium is leveled. For $\varepsilon \geq 2.5 \%$ for nitrided specimens and for $\varepsilon \geq 4 \%$ for improved specimens, their durabilities in air and in a corrosion medium coincide (Fig. 3). In this case, it is clearly seen that, starting from the deformation amplitude $\varepsilon \geq 2.5 \%$, the use of NGD to increase the low-cycle durability is not efficient.

The durability of details of friction units is determined mainly by the resistance to the fatigue high-cycle fracture under the conditions of contact of details of the equipment at food enterprises with CM. For the definite conditions of loading of a friction contact, the low-cycle fracture can transit to the high-cycle fracture and vice versa. The studies indicate (Fig. 4) that the high-cycle durability of 40Kh steel after NGD increases by at least $35 \%$ and by $30 \%$ in an acidic medium.

It is known that if a metal operates under the action of stresses, the diffusion layer hampers the rise of dislocations to the surface, by preventing the initiation and propagation of microcracks. In addition, the durability limit of nitrided steels in corrosive media increases with the corrosion resistance [6] and the residual compressive stresses after NGD in surface layers.

The application of the method of active planning of experiments enabled us to develop a statistical model of high-cycle lifetime of $40 \mathrm{Kh}$ steel in the acidic model medium:

$$
N \cdot 10^{7}=15.52-0.025 T+0.008 C_{\mathrm{N}_{2}}+0.0006 P,
$$

where $T$ is the nitriding temperature, ${ }^{\circ} \mathrm{K}, C_{\mathrm{N}_{2}}$ is the content of nitrogen in a gas mixture, $\%$, and $P$ is its pressure, $\mathrm{Pa}$.

Relation (2) indicates that the number of cycles prior to the fracture $N$ is mostly affected by the nitriding temperature whose increase leads to a decrease in the durability. The fatigue durability of $40 \mathrm{Kh}$ steel in an acidic medium increases with the content of nitrogen and the pressure of a gas mixture.

\section{CONCLUSIONS}

The studies of the low-cycle durability of structural steels after NGD in an acidic model medium show that it is mainly affected by the nitriding temperature. As the nitriding temperature increases, the low-cycle durability decreases. The number of cycles prior to the fracture decreases more rapidly, as the content of carbon in 
the matrix and the degree of its doping increase. An increase in the content of nitrogen and in the pressure of a gaseous medium does not influence practically the low-cycle durability of nitrided steels in an acidic medium. During the nitriding, the focus of cyclic fracture is located usually under the surface nitride layer. Therefore, its composition has practically no influence on the fatigue characteristics of steels. An increase in the resistance to the low-cycle fracture is determined by the strength characteristics of the diffusion layer ( $\gamma$ - and $\alpha$-phases). The tests for static strength show that NGD of steels increases their strength characteristics $\left(\sigma_{\mathrm{u}}\right.$ and $\left.\sigma_{\mathrm{y}}\right)$ and decreases simultaneously the plasticity. It is established that the number of cycles prior to the fracture under a low-cycle loading of $40 \mathrm{Kh}$ steel in an alkaline solution is even larger than in air. This is explained by the formation of a hydroxide layer blocking the rise of dislocations to the surface. If the amplitude of vibrations $\varepsilon<0.5 \%$, the difference in the durabilities of nitrided and nonhardened steels under a low-cycle loading is insignificant. For $\varepsilon \geq 2.5 \%$ for nitrided and $\varepsilon \geq 4 \%$ for improved specimens, their durabilities in air and in the corrosive medium coincide. In this case, by starting from the deformation amplitude $\varepsilon>0.25 \%$, the use of NGD to increase the low-cycle durability is not efficient. The high-cycle durability is mainly affected by the nitriding temperature: as it increases, the durability of nitrided steels decreases. The fatigue high-cycle durability of nitrided steels increases with the content of nitrogen and the pressure in a gas atmosphere: for example, it is higher for $40 \mathrm{Kh}$ steel by at least $35 \%$ in air and by $30 \%$ in an acidic medium.

\section{REFERENCES}

1. M. S. Stechyshyn, N. M. Stechyshyna, and A. V. Martynyuk, Cavitation-Erosion Wear Resistance of Details of the Equipment of Milk Plants [in Ukrainian], KhmNU, Khmel'nyts'kyi (2018).

2. I. M. Pastukh, Theory and Practice of Hydrogenless Nitriding in a Glow Discharge [in Russian], KhFTI, Khar'kov (2006).

3. M. S. Stechyshyn, G. M. Sokolova, and Yu. M. Bilyk, "Influence of power and mode parameters on the phase structure and microhardness of ion-nitrided structural steels," Probl. Tertya Znosh., No. 2, 56-64 (2017).

4. V. I. Tkachev and Yu. I. Babei, "Machine IP-2 for the testing of metals for low-cycle fatigue in liquid media," Fiz.-Khim.Mekh.Mater., 1, No. 2, 228-229 (1966).

5. A. V. Prokopenko and V. N. Torgov, "A method of testing of compressor blades of a gas turbine engine for fatigue in the corrosion medium," Probl. Prochn., No. 4, 107-109 (1980).

6. M. S. Stechyshyn, A. V. Martynyuk, Yu. M. Bilyk, V. P. Oleksandrenko, and N. M. Stechyshyna, "Influence of the ionic nitriding of steels in glow discharge on the structure and properties of the coatings," Fiz.-Khim. Mekh. Mater., 53, No.3, 49-55 (2017); English translation: Mater. Sci., 53, No. 3, 343-350 (2017). 